\title{
is Research Suare \\ Isolation and characterization of a new crAss-like phage from the human gut
}

\section{Emma Guerin}

Andrey N. Shkoporov

Stephen R. Stockdale

Joan Colom Comas

Ekaterina V. Khokhlova

Adam G. Clooney

Karen M. Daly

Lorraine A. Draper

Niamh Stephens

Dimitri Scholz

R. Paul Ross

Colin Hill

\section{Video Byte}

Keywords: bacteriophages, crAssphage, crAss-like phages, human gut phageome, human microbiome, phage-host interactions, Bacteroides xylanisolvens, fecal fermentation, phage isolation, characterization, Microbiome

Posted Date: October 14th, 2021

DOI: https://doi.org/10.21203/rs.3.rs-968271/v1

License: (9) This work is licensed under a Creative Commons Attribution 4.0 International License. Read Full License 


\section{Abstract}

CrAss-like phages are the most abundant family of bacteriophages in the human gut. Despite their abundance, only three types of crAss-like phages have been isolated in pure culture. Now, a new study reports the successful isolation of a new crAss-like phage, $\Phi$ crAss002. Researchers used fecal fermentation with antibiotics to select for gram-negative bacteria including Bacteroides, a favorite target of crAss-like phages. That led to the isolation of $\Phi$ crAss002, which infects Bacteroides xylanisolvens. Experiments showed that, despite being a lytic phage, $\Phi$ crAss002 did not form plaques on bacterial lawns or lyse liquid cultures of sensitive bacteria, even at high titers. $\Phi c r A s s 002$ and B. xylanisolvens can coexist at high levels in co-cultures, which is consistent with their co-abundance in the human gut. This coexistence between phage and host is also found in the previously described $\Phi$ crAss001. While more research is needed to understand how such stable co-cultures form, the isolation and characterization of new crAss-like phages like this offers insight into the interactions between phagome, bacterial microbiome, and human host. 